\title{
The Functions and Expressions of English Euphemism in Business Negotiation
}

\author{
Tingting Xiao \\ Foreign Languages Department \\ Jilin Institute of Chemical Technology \\ Jilin, China 132022
}

\begin{abstract}
After China joining to WTO, China's economy is developing rapidly. The connection between China and the world is closer than before. Under the situation of economic globalization, business activities among countries increase frequently and business negotiation plays a very important role. Because negotiators come from different countries or regions, there are difficulties in language communication, and they all have different characters which cause conflict, and even to make negotiation suspended or failure. Euphemism is a general but extremely important language phenomenon in modern society. It is a kind of language expression which is produced in order to help people achieve practical results in social events. What's more, euphemism is an effective way to coordinating the interpersonal relationship. Especially in business negotiation, euphemism plays a role of "lubricant". The proper use of euphemism can ease the tension, avoid conflicts, break the ice and increase the chances of success in negotiation. What's more, it can maintain the friendly relations between the both sides, so euphemism is an effective way to capture business opportunities and expand the market. It is meaningful for us to understand and study euphemism in business negotiation. Therefore, this paper studies the function and expression to analysis its methods of using and significance in business negotiation.
\end{abstract}

Keywords-business negotiation; English euphemism; function; expression

\section{INTRODUCTION}

In our everyday life, misunderstanding or contradictions may come into being because of inappropriate use of language. English euphemism plays an important role in lubricating people's communication and maintaining a good interpersonal relationship. That means euphemisms can be used for avoiding taboos and showing politeness in our daily life.

Euphemism is a common language strategy in communication. When it is difficult or unsuitable for people to say something directly, they always use euphemisms consciously or unconsciously. People use them with different intentions and for different purposes. In fact, euphemisms act as one of the "lubricants" in daily communication and in the exchange of information to such an extent that "without euphemisms, the world would come to a halt because conflicts and resentments would spring up among people" (Enright1985:113).
So, euphemism is always a hot topic that studied by lots of experts and scholars both at home and abroad. Euphemism is often limited to rhetoric and is considered as a tool that writers or speakers use to make their expressions more graceful. Moreover, the research of euphemism mainly centers on the lexical level abroad and rhetorical techniques in China. Much to people's satisfaction, the study of euphemism has been extended to tactful expressions in communication and textual level with the development of social-linguistics, psycho-linguistics, and the deeper research of the relationship between culture and language. Besides, experts and scholars have made multi-angle studies on euphemism and have made great achievements which contribute greatly to people's understanding and the application of euphemisms in their interpersonal communication. However, studies about English euphemisms in business negotiation are far from satisfactory.

The intercultural communication becomes more and more frequent with the increasing exchange among business from various countries. In the intercultural exchange, the negotiators of various backgrounds should know something about each other's culture, customs and history. And attempt to understand the differences between countries so that collision could be avoid. As a common phenomenon in human languages and society, Euphemism is also widely and flexibly used in business negotiations. Its pragmatic functions and different expressions are extremely beneficial to businessmen. The use of euphemisms in business activities plays an increasingly greater role in helping grasp business chance, promote products, expend to new markets and so on. However, business negotiation failure continually because of businessmen's inappropriate use of euphemisms. Thus, a systematic study of the functions and expressions of English euphemism in business negotiation is very important.

On the basis of other experts and scholars' research, I try to make a tentative study of euphemisms in business negotiation within the framework of adaptation theory.

\section{THE INTRODUCTION OF EUPHEMISM}

Euphemism is a common language strategy in communication. When it is difficult or unsuitable for people to say something directly, they always use euphemisms consciously or unconsciously. People use them with different intentions and for different purposes. In fact, euphemisms act 
as one of the "lubricants" in daily communication and in the exchange of information to such an extent that "without euphemisms, the world would come to a halt because conflicts and resentments would spring up among people" (Enright1985:113).

\section{A. The Definition of Euphemism}

The term "euphemism" comes from the Greek "eu", meaning "good", and "pheme", meaning "speech" or "saying", and thus it literally means "to speak with good words" (Halliday 2001).By the 1580s,British writer George Blant used the term "euphemism" in English for the first time, defining it as "a good or favorable interpretation of a bad word" (Neaman \& Silver1983:4). As Rawson said in 1981, euphemisms are "mild agreeable or roundabout words used in place of coarse, painful, or offensive ones". And he has also explained the reasons for the existence of euphemisms, which provide the key on the understanding of euphemisms. They conceal the fear of human beings, like the supernatural and the death; they cover up the facts of life, like sex, reproduction and excretion; and they are loved by those individuals, who are anxious to present only the handsomest possible images of themselves to the world (ibid). In current English dictionaries, euphemism is defined as follows:

A polite, tactful, or less explicit term used to avoid the direct naming of an unpleasant painful or frightening reality. (Webster's Third New International Dictionary, 1961)

A polite word or expression that you use instead of a more direct one to avoid shocking or upsetting someone. (Longman Dictionary of Contemporary English, 1995)

Using of pleasant, mild or indirect words or phrases in place of more accurate or direct ones. (Oxford Advanced Learner's English-Chinese Dictionary, 4th edition, 1999)

In my opinion, Euphemism is a mean of achieving one's own purpose and meanwhile makes other feel happy. Although those experts and scholars gave different definitions, the common point is that euphemism is a polite and kind expression to communicate with others.

\section{B. The Formation of Euphemism}

The formation of euphemism is on our way, when it comes to how to put euphemisms into practice. "It's generally believed that there are three ways to form an authentic euphemism: lexical means, grammatical devices and rhetorical means." (Linfoot-Ham, 2005) Here I will give some examples about these three types of formations.

\section{1) Lexical meaning}

a) Loanwords as euphemism: According to the theory of psychology, foreign language can establish a certain psychological distance between the speaker and listener. Thus, it is quite often to find that loanwords act as euphemisms in conversation. Due to the close relationship between British and French, many French loanwords in English are easy to find acting this role. b) Use of abstract and general words: Using fuzzy words most of time can blur the explicit but not the desirable meaning of words. Thus creates the euphemistic effect. And then if you find that "social disease". It may really indicate "syphilis". The expression "you know what" can denote anything that can be inferred from the context and that is familiar to both sides of talking.

2) Grammatical devices: The famous American linguist Bolinger, Dwight once said that "Euphemism is not restricted to the phonetic or lexical level; there are various grammatical ways of toning something down without actually changing the content of the meaning." (1981:148). Grammatical device is an effective way to formulate euphemistic expression. Grammatical devices include negation, variation of tense, passive voice, skillful use of personal pronouns, comparison and so on. Here we three major devices.

a) Negotiation: Negotiation is wildly used in euphemisms in all languages. Using negation style to express can make the statement tone less fierce than direct expression. For example, "I don't think this is possible" may make people feel better than "I think it is impossible." The first expression can give hope to the listener that maybe there is some possibility, but the latter expression directly closes the door of hope.

b) Variation of tense: The most widely used tense in euphemisms may be the past tense, As we all know, past tense means the things past, thus it can create a sense of emotional remoteness, exactly what we need when we want to drop a hint to the listener, and that is euphemistic. For instance, "I thought someone could help me with it" the true meaning of speaker is "someone come to help me".

c) The passive voice: One benefit of using passive voice is that it avoids mentioning the agent of an action thus to achieve the goal of politeness or kindness, particularly when criticism should be conveyed. For instance, "We don't allow you to take books out of the room." can be changed to "No books are allowed to take out of the room." In this way, the tone of the speech is much more acceptable to people. In business negotiations, no one can avoid argument. In case of tense atmosphere, decent expressions can bring about unexpected effect. About the expressions of euphemisms in business negotiation, I will give more details in chapter three.

3) Rhetorical means: About the relationship between rhetoric and euphemisms, we can cite a famous saying. It says that "From the rhetorical point or view, euphemism is a kind of figure of speech, a way to use neutral or elegant word or expression deliberately instead of a sensitive or vulgar one so as to establish a graceful and desirable public image."(Wang, Xijie 2000:174). Though, euphemisms may not all employ rhetorical means, it's definitely an effective way to create euphemistic meaning. They can take the forms of metaphor, metonymy, personification, hyperbole, periphrasis and so on. 
Through the differences in wording and perspectives, these definitions have a same point. A euphemism is a kind of expression intended by the speaker to be less offensive, disturbing, or troubling to the listener. It can make the unpleasant things sound happier, and make people feel good; moreover, it can make both the speaker and the hearer safe without losing face. However, euphemisms are not confined to individual words. They can be a sentence or even a larger structural unit (Shu Dingfang \& Xu Jinyuan, 1995). Euphemisms do not live in a vacuum. They are generated and used to serve a certain function (mainly to create a better effect and establish a good tie between interlocutors) in a given social communication. Their validity relies on the psychological need of their users, who deem certain expressions offensive or unpleasant and substitute new expressions for the dispreferred ones.

\section{THE FUNCTIONS OF EUPHEMISM IN BUSINESS NEGOTIATION}

Euphemism in business English is a kind of expression in a polite, indirect and face saving way to substitute the ones with disagreeable or less respectful meaning. In fact, it is more than just euphemistic words and phrases that are used in common situation, it's a kind of tact communication that is applied to achieve satisfactory communicative effects.

\section{A. Significance of Euphemism in Business Negotiations}

Negotiation refers to a dialogue between negotiation parties, intended to reach an understanding, resolve trade dispute, or gain advantage in outcome of dialogue, to produce an agreement upon courses of action, and achieve their interests.

It is long believed that affinity can greatly promote business prosperity. As an old saying goes in China, "Affinity makes money." Where does this affinity come? It is one's wording that of great importance. A successful businessman can always make his customers feel comfortable when talking with him. It is certain that he must be a master in using all kinds of language skills, especially using euphemisms.

In business negotiations, likewise, people also have to pay attention to tactful utterances and communicational skills. Among them, euphemism, as a useful language skill, is commonly used in the business negotiation. Properly using euphemisms can help to gain confidence from customers, and build up long term cooperation.

"Language is power." as a famous French writer said, how to negotiate effectively for achieving the negotiation purposes plays an important role in the business activities. This requires the use of a lot of euphemism strategies. The smooth development of business negotiation depends on good social relationship.

\section{B. Being Polite and Saving the Faces of Both Sides}

In business negotiation, there will be conflict inevitably when both sides want to persuade others to accept their requests or suggestions. If the language is too sharp or direct, it will make others feel overbearing and even hurt their face. What's worse, it may lead to the failure of negotiation.

So the strong desire to avoid offending adversaries is one of the main motivations to use euphemisms. To avoid offending adversaries and to save face are closely related. Therefore, the use of euphemism is adapted to politeness and face-saving motivation.

Face refers to the public self-image of a person. That is to say, in human communication, people want to be respected. To this extent, politeness in communication can use as the means to show awareness of other people's face. Face threatening act is a language behavior, which threatens another individual. And a face-saving act refers to the language behavior, which can lessen the possible threat (Yule2000). Since people all wanted to be respected, in business negotiation, two parties involved try best to save each other's face and create a harmonious atmosphere even if they have contradictory points of views.

The following examples can reflect this point.

A: Send us the samples as soon as possible.

B: Would you please send us the samples as soon as possible?

As is discussed earlier, B is more euphemistic than A, A is an imperative sentence which sounds like an order. And as a result, the recipient will feel impinged or not respected. Only the proper use of euphemism can make negotiators feel respected by the other side, and maintained his face.

\section{Avoid Deadlock to Increase the Chances of Success}

Using euphemisms can avoid deadlock in business negotiations. When some phrases are full of force in the process of negotiations, it will make negotiators fall into a difficult positions and cause the negotiation to be a deadlock. For instance, such phrases as "that's the last choice" "take it or leave it" or "that's nonnegotiable" will indicate that the utter is going to force his adversary to make the last decision. However, by using such euphemistic expressions as conditional sentences and vague words, the utter can increase the flexibility of his speech and avoid coming into a deadlock.

In the course of business negotiations, it is impossible for negotiators to force others to reach an agreement. Thus, they must leave some room to opponents so that they can change their standpoint without losing of their face. In addition, vague wording can help win the opponent psychologically. By using of the vague words, the speaker can increase the elasticity and flexibility to avoid getting a deadlock. The following are opposite examples.

A: This is our rock-bottom price, Mr. Lin, we can't make further concession.

B: If that's the case, there is not much point in further discussions we might as well call the whole deal off.

The phrase "rock bottom price" makes the negotiation go stuck and the speaker at a disadvantageous position. Obviously, such negotiations easily break off. 


\section{Establish a Long-term Friendly Business Relationship}

As we all know, in the process of business negotiation, the most basic elements that affect the behavior of negotiators is the economic interests and mood. Economic interest is the purpose of negotiation, and the mood is the key to determine whether it succeeds or fail. Euphemism can make the negotiators to maintain a good mood to continue the negotiation. On the contrary, if they only consider their own interest and ignore the other side's feeling, it will affect the long-term cooperation.

Business negotiation is actually a kind of economic activity through language. The success of business negotiation depends largely on the appropriate use of language to some extent. Both parties have to cooperate with each other as well as compete against each other, either party endeavor to maximize its own benefit while maintaining cooperation with the other. Undoubtedly, this goal has to be achieved through the appropriate use of language.

In international business negotiation, euphemistic strategies are frequently used because euphemistic expressions can create a friendly and cooperative atmosphere between the two parties involved, relieve the tension of negotiation and break the deadlock when a negotiator expresses different opinions. Euphemisms can be easily accepted by the business partners psychologically because they serve to avoid embarrassment and conflicts. Using euphemistic strategies properly can make both parties feel comfortable and pleasant. Sometimes, when improper strategies are adopted, the business relationship between the negotiators will be broken. Thus, as a negotiator, it is very important to make use of various euphemistic strategies properly.

In a word, the correct use of euphemism can ease the tension of negotiation, maintain the cooperation of both sides and avoid the deadlock.

\section{THE EXPRESSIONS OF EUPHEMISM IN BUSINESS NEGOTIATION}

Euphemism in business English is a kind of expression in a polite, indirect and face saving way to substitute the ones with disagreeable or less respectful meaning. In fact, it is more than just euphemistic words and phrases that are used in common situation, it's a kind of tact communication that is applied to achieve satisfactory communicative effects.

\section{A. Hedging Expression}

Hedging Expression is often applied in business negotiations by negotiators to hide their own opinions by means of hedging words or phrases for not showing their disagreement too obviously. When disagreement or criticism is unavoidable, the following expressions are often used, such as "I'm afraid that...", "it seems that...", "a little", "quite", "sort op" or "rather", and etc. For example:

(I) A: We can't agree to your request.

B: I am afraid that we can't agree to your request.

(II) A: It was unwise of you to delay the delivery.
B: It seems to me that it was unwise of you to delay the delivery.

Sample I is a kind of disagreement while II is a criticism, both of which will threaten the hearer's face. But by adding the hedging phrases "I'm afraid" and "It seems to me", the speaker reduces the force and makes the words more acceptable.

\section{B. Syntactic Strategies}

Syntactic strategies refer to the use of various syntactic devices including tense, passive voice, subjunctive mood, and transitional word "but", conditional indicate or "if" and interrogative sentences to achieve euphemistic effects.

1) Use of tense: Past tense can be used to express politeness so that euphemistic effect can be achieved. As the tense is switched from present to past, the speaker distances himselffrom the "here and now". And the more remote the speaker using the past tense, the more likely it isto save the hearer's face. Look at these three examples below:

(I) A: Can you send us a catalogue by airmail?

B: Could you send us a catalogue by airmail?

C: I wondered whether you could send us a catalogue by airmail.

We can feel that politeness in example I increase because of theuse of the past tense.

2) Use of passive voice: In business negotiations, negotiators often adopt active voice to express their opinions and viewpoints briefly and clearly. Sometimes, passive voice is more appropriate and favorable for negotiators especially when one speaker wants to express such ideas as request, suggestion, or denial because he should avoid pinning down someone who is responsible for the action which causes embarrassment or displeasure in business negotiations.

Passive voice is often employed to minimize imposition on hearers.

(I) Shipment should be made before October; otherwise we are not able to catch the season.

This form not only distances the hearer from the relative matter, as compared with "You should make the shipment before October, otherwise...". It seems that the expression "shipment should be made" is requested by no-one in particular and must be effected by no-one in particular.

Passive voice may be used to remove the mentioning of the speaker, as is shown in the following:

(I) A: I regret that the cargos are not in line with the requirements specified in the documentary bill.

$\mathrm{B}$ : It is regretted that the cargos are not in line with the requirements specified in the document bill.

(II) A: I would appreciate it if you could make 5,000 tons for February shipment and the other 5,000 tons for March shipment; at the price quoted in the sheet. 
B: It would be appreciated if you could make 5,000 tons for February shipment and the other 5,000 tons for March shipment, at the price quoted in the sheet.

In the above examples, the second sentences sound much more polite than the first sentences because of passive voice. Be means of the third personal pronoun "it", the speaker, who is performing the face-threatening acts of denying, criticizing and requesting in these sentences, is avoiding the face threatening act.

Furthermore, passive voice can also be used to eliminate the direct meaning of the hearer, looking the following two examples.

(I) A: What if you cannot complete the inspection within the time limit?

B: What if the inspection cannot be completed within the time limit?

(II) A: Obviously, you made a very careless mistake here.

B: A very careless mistake was made here.

Sample (I) A and (II) A seriously threaten the face of the hearers when they are pointed out as the targets of warning and criticism. These two sentences are very rude and may do harm to cooperative relationship in business negotiation. In (I) $\mathrm{B}$ and (II) $\mathrm{B}$, the hearers are omitted and their faces are saved because of passive voice.

Finally, passive voice can be used to avoid making reference to both the speaker and the hearer.

A: You didn't list the specification we need.

B: The specification we need wasn't listed here.

$\mathrm{C}$ : The specification as required wasn't listed here.

A can be regarded as the most impolite expression by making reference to both the speaker and the hearer. B, without making reference to the hearer, can be a little more polite by hinting that no one particular should be complained about or criticized in this case. And without making reference to both the speaker and hearer, $\mathrm{C}$ is the most polite one because it saves the face of both the speaker and the hearer.

In a word, passive voice can be used to avoid making direct reference to the agent of a speech act. Though the elimination of the agent, the utterance becomes much more indirect and reduces the danger of face threats.

3) Use of subjunctive mood: There will be problems such as price, shipment, claim, insurance and so on. And it is inevitable to encounter a tough opponent, Using too much imperative sentence will make the expression stiff. When you are facing such an opponent, you can try to use the subjunctive mood to discuss with him or her in order to lose the spirit of opponent gradually and make negotiations in an atmosphere of harmony. In trade negotiations, if you can use some interrogative sentences instead of imperative sentences and affirmative sentences, it will receive better results. Try to compare the following two sentences:

\section{A: You must quote us CIF prices. \\ B: I would rather you quoted us CIF prices.}

From these two sentences, subjunctive mood B is more polite than affirmative sentence A. When negotiators talk about some sensitive topics, such as price topic. If you said too directly, it will make others feel there is no room for negotiation. Subjunctive mood, which will make the utterance more implicit and indirect and turn the hard tone into a soft one, could be favored as an effective strategy to reduce the impingement on hearers and save hearers' face to a degree.

4) Use of "But": There are many discrepancies and disagreements between business negotiators. However, it is proved to be unfavorable to show the disagreement directly in business negotiations. One of the effective ways to show disagreement indirectly is the use of the transitional word "but" which has the power to conceal the force of disagreement. The following are very good examples.

(I) A: It's impossible to accept the price.

B: I understand your position, but it's impossible to accept the price.

(II) A: It's too, expensive to have all, these technical data translated into Chinese.

B: You may be right, but it's too expensive to have all these technical data translated into Chinese.

(I) $\mathrm{B}$ and (II) $\mathrm{B}$ threaten the hearers' face less seriously than (I)A and (II) A, because the use of "but". With this strategy, the speaker makes his unpleasant idea more acceptable.

In (I) and (II), the speaker simply admits that he is impinging on

the hearer's face.

5) Use of "If": The use of "if" can turn command into a polite request or suggestion. For example:

A: You should dispatch the goods as soon as possible.

$\mathrm{A}$ is an order with a tough tone which deprives the hearer of his freedom. The hearer's face is not saved. This is an explicit face-threatening act. The hearer will feel awkward or even angry with the speaker. However, the use of the ifclause reduces the force of the order.

As we can see from the above-mentioned examples, ifclause also functions pragmatically as a hedge. The combination of these if-clauses with a direct request is one of the standard ways of polite request in business English.

6) Use of interrogative sentences: In business negotiations, interrogative sentences are often used. The main purpose of using interrogative sentences is to obtain information. Thus, making appropriate sentences is of great importance in business negotiations.

According to the politeness scale, the more indirect the question is, the more polite and euphemistic the speaker is. Thus, interrogative sentences with such modals as ought to, 
would, should, would be more polite than interrogative sentences with such modals as can, may, must, will, shall.

(I) Would you deliver the first 500 in four weeks and the second part two weeks later?

(II) Could you give us some idea about your price for a bicycle?

In the above examples, modals make the requests indirect and polite, because in these interrogatives the speaker doesn't assume that the hearer is able and willing to do what he requests or suggests. Thus, the hearer gets much freedom and the speaker in such a soft tone would not lose his face even if he is rejected.

Let's look at the following examples.

(I) A: We want to increase our supply by one ship load.

B: What would you say if we increase our supply by one ship load?

(II) A: I want to have a look at your specification.

B: Could you show me your specification?

\section{Conceding Strategy}

Conceding strategy is usually adopted when people refuse to admit their mistake. In that case any explanation is futile. Under this circumstance, one can reduce the embarrassing situation by pointing out that hearer(s) can find out the reasons for some kinds of problems themselves, which can save the hearer's face. good.

A: We know that the quality of your products is not so

B: We know where you are about the quality of your products.

In example $\mathrm{A}$, the speaker makes his business partner embarrassed by a direct statement. In example B, the speaker bears in mind the bad quality of the products. He uses the euphemistic expression "where you are" to save the hearer's face and avoid direct verbal conflict.

I analyzed the commonly used euphemistic expressions in detail in this chapter, with a series of examples from actual business negotiations. From the above analysis, we can see that euphemistic expressions are very useful in the contexts of international business negotiation. They can increase the negotiating flexibility and possibility and improve the negotiating results.

According to these analyses, I come to a conclusion that the proper use of polite language and euphemistic tone in appropriate conditions can create a harmonious atmosphere for negotiations so that negotiators could get a high quality business communication. What's more, it will greatly improving the flexibility of negotiation and promote the probability of success.

Euphemism plays a very important role in business negotiation, because it is helpful for the two parties to strengthen mutual belief and understanding, and sometimes it can be a decisive factor for a successful negotiation. So, it is necessary for us to study the correct ways or using euphemism.

\section{CONCLUSION}

Euphemism in business English is a kind of expression in a polite, indirect and face saving way to substitute the ones with disagreeable or less respectful meaning. In fact, it is more than just euphemistic words and phrases that are used in common situation, it's a kind of tact communication that is applied to achieve satisfactory communicative effects.

In this article, I have focused my research on every aspect of English euphemism in business applications. I started from basic introduction to euphemism including its definitions and formation. In the history, many people have done a lot of research on it, and based on their conclusions, and on the basis of myself experience in business field, I discussed about several important functions in the process of business negotiation. Then I focus on the expressions of euphemism in business negotiation. That is to dig out some supplementary points about euphemism which help negotiators to deal more properly and avoid making mistakes and embarrassments in general business activities.

In general, business negotiation is a complicated activity, which is like a war without fire. It is a debating subject that is attractive and full of challenges forever. To win in this war, proper use of language expressions is necessary. Successful negotiators regard language not only as a communicative tool, but also as a useful strategy. On many occasions in business negotiations, euphemism is employed as a common strategy to make the negotiation appropriate and smooth. As a negotiation strategy, euphemism acts as a lubricant, which helps make the process of negotiation smoothly.

\section{REFERENCES}

[1] Bolinger, D. A\& Sears, D.A. Aspects of Language [M].Harcourt Brace Jovanovich Inc, 1981:148

[2] Halliday, M,A.K. \& Hasan, R. Language, Context and Text: Aspects of Language in a Social-Semantic Perspective [M].Geelong, Victoria, Aus: Deakin University Press, 1985

[3] Linfoot-Ham, K. The Linguistics of Euphemism: A Diachronic Study of Euphemism Formation [J].Journal of Language and Linguistics, Vol.4 No.2, 2005, ISSN1475-8989

[4] Mencken, H.L. The American Language[M]. New York: Alfred A KNOPE New York, 1937:96-101

[5] Neaman J.S \& Silver C.G ,. Kind Words: A thesaurus of Euphemisms [M]. New York, Facts on File World Publishing Corp, 1983:4

[6] Lin Yuhui. The Function and Grammar Means of Euphemism in Business Negotiation [J]. Science and Technology Information, 2009(5): 250 林于会. 委婉语在商务英语谈判中的功能及语法手段 [J]. 科技信息, 2009（5）:250

[7] Nie Wei, Meng Siyu. Application of English Euphemism in Business Negotiation[J]. Business English Language, 2010(00): 110-114 聂 薇, 孟丝雨. 英语委婉语在商业谈判中的应用研究 $[\mathrm{J}]$. 商务英语语 言, 2010 (00) : 110-114

[8] Shu Dingfang.New Exploration of Euphemism [J]. Foreign Languages, 1989(3):28-34 束定芳. 委婉语新探 [J]. 外国语, 1989 (3) :28-34 
[9] Wang Xijie. Introduction to Rhetoric [M]. Hangzhou: Zhejiang Education Press, 2000:174 王希杰. 修辞学导论 [M]. 杭州: 浙江教 育出版社, 2000: 174

[10] Zhang Hongguo. Language Means of Euphemism Expression in English [J]. Journal of West China College, 2004(1):136-139 张宏国. 英语中委婉语表达的语言手段 [J]. 皖西学院学报, 2004 (1) : $136-139$ 